\title{
Technical Note: Continuity of MIPAS-ENVISAT operational ozone data quality from full- to reduced-spectral-resolution operation mode
}

\author{
S. Ceccherini ${ }^{1}$, U. Cortesi ${ }^{1}$, P. T. Verronen ${ }^{2}$, and E. Kyrölä ${ }^{2}$ \\ ${ }^{1}$ Istituto di Fisica Applicata "N. Carrara" (IFAC) del Consiglio Nazionale delle Ricerche (CNR), Firenze, Italy \\ ${ }^{2}$ Earth Observation, Finnish Meteorological Institute, Helsinki, Finland
}

Received: 24 October 2007 - Published in Atmos. Chem. Phys. Discuss.: 16 January 2008

Revised: 31 March 2008 - Accepted: 31 March 2008 - Published: 21 April 2008

\begin{abstract}
MIPAS (Michelson Interferometer for Passive Atmospheric Sounding) is operating on the ENVIronmental SATellite (ENVISAT) since March 2002. After two years of nearly continuous limb scanning measurements, at the end of March 2004, the instrument was stopped due to problems with the mirror drive of the interferometer. Operations with reduced maximum path difference, corresponding to both a reduced-spectral-resolution and a shorter measurement time, were resumed on January 2005. In order to exploit the reduction in measurement time, the measurement scenario was changed adopting a finer vertical limb scanning. The change of spectral resolution and of measurement scenario entailed an update of the data processing strategy. The aim of this paper is the assessment of the differences in the quality of the MIPAS ozone data acquired before and after the stop of the operations. Two sets of MIPAS ozone profiles acquired in 2003-2004 (full-resolution measurements) and in 2005-2006 (reduced-resolution measurements) are compared with collocated ozone profiles obtained by GOMOS (Global Ozone Monitoring by Occultation of Stars), itself also onboard ENVISAT. The continuity of the GOMOS data quality allows to assess a possible discontinuity of the MIPAS performances. The relative bias and precision of MIPAS ozone profiles with respect to the GOMOS ones have been compared for the measurements acquired before and after the stop of the MIPAS operations. The results of the comparison show that, in general, the quality of the MIPAS ozone profiles retrieved from reduced-resolution mea-
\end{abstract}

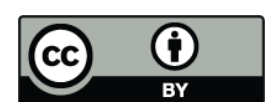

Correspondence to: U. Cortesi (u.cortesi@ifac.cnr.it) surements is comparable or better than that obtained from the full-resolution dataset. The only significant change in MIPAS performances is observed at pressures around $2 \mathrm{hPa}$, where the relative bias of the instruments increases by a factor of 2 from the 2003-2004 to 2005-2006 measurements.

\section{Introduction}

The atmospheric chemistry payload onboard the ENVIronmental SATellite (ENVISAT) of the European Space Agency (ESA) consists of three instruments that are capable to retrieve vertical concentration profiles of several trace gases from observations in the middle infrared (MIPAS), visible and ultraviolet (GOMOS and SCIAMACHY) spectral regions (Nett et al., 2001). In particular, all these sensors provide, as part of their level 2 operational products, heightresolved information on the ozone distribution from the upper troposphere to the mesosphere. This offers a unique opportunity for intercomparison and cross-validation of ozone data derived from different measurement techniques and observation strategies, thus making possible precise assessments about instrument performances and about the quality of the retrieval products. In this paper, we compare vertical profiles of ozone Volume Mixing Ratio (VMR) obtained from selected pairs of coincident measurements by MIPAS and GOMOS, with the aim of checking whether MIPAS ozone data quality remained stable during the period from July 2002 to May 2006. The motivation for verifying the continuity of MIPAS ozone measurement performances arises from the interruption in instrument operations that occurred at the end of March 2004 and from the changes implemented

Published by Copernicus Publications on behalf of the European Geosciences Union. 
Table 1. Comparison between the MIPAS observation modes adopted before and after January 2005

\begin{tabular}{llll}
\hline & Before January 2005 & \multicolumn{2}{c}{ After January 2005 } \\
\hline & Nominal mode & Nominal mode & UTLS-1 mode \\
\hline Spectral resolution & $0.025 \mathrm{~cm}^{-1}$ & $0.0625 \mathrm{~cm}^{-1}$ & $0.0625 \mathrm{~cm}^{-1}$ \\
Sweep time & $4.5 \mathrm{~s}$ & $2.1 \mathrm{~s}$ & $2.1 \mathrm{~s}$ \\
Scan measurement time & $76.5 \mathrm{~s}$ & $56.7 \mathrm{~s}$ & $39.9 \mathrm{~s}$ \\
Number of altitude grid points & 17 & 27 & 19 \\
Horizontal sampling step & $550 \mathrm{~km}$ & $410 \mathrm{~km}$ & $290 \mathrm{~km}$ \\
Altitude grid & Fixed & Floating & Floating \\
Vertical sampling step & $3.0 \mathrm{~km}$ [at 6-42 km] & $1.5 \mathrm{~km}$ [at 7-22 km] & $1.5 \mathrm{~km}$ [at 8.5-22 km] \\
& $5.0 \mathrm{~km}$ [at 42-52 km] & $2.0 \mathrm{~km}$ [at 22-32 km] & $2.0 \mathrm{~km}$ [at 22-28 km] \\
& $8.0 \mathrm{~km}$ [at 52-68 km] & $3.0 \mathrm{~km}$ [at 32-47 km] & $3.0 \mathrm{~km}[$ at 28-34 km] \\
& & $4.0 \mathrm{~km}$ [at 47-63 km] & $4.5 \mathrm{~km}$ [at 34-52 km] \\
\hline
\end{tabular}

after January 2005 in the optical configuration and in the measurement scenario. In fact, MIPAS performed observations at full-spectral-resolution $\left(0.025 \mathrm{~cm}^{-1}\right)$ for the first two years of the ENVISAT mission (March 2002-March 2004). A gap in instrument acquisitions exists from March 2004 to January 2005, when operation were suspended to investigate the source of anomalies observed in the interferometric drive unit (Frerick et al., 2006). MIPAS operations started again in January 2005, at reduced-spectral-resolution $\left(0.0625 \mathrm{~cm}^{-1}\right)$ and using a new measurement scenario. Results of level 2 analysis for a limited number of orbits in the period 20052006 were made available for validation purposes. Based on the assumption that the quality of the ozone products derived from GOMOS nighttime measurements was fairly constant during the entire period under investigation and considering that MIPAS ozone operational data from the full-spectralresolution mission have already undergone an extensive validation process (Cortesi et al., 2007), we can use the results of the comparison between coincident ozone data from MIPAS 2003-2004 and 2005-2006 periods against GOMOS measurements for an assessment of the quality of the $\mathrm{O}_{3}$ profiles retrieved from MIPAS reduced-resolution measurements. In the following sections, we will first provide all relevant information about MIPAS and GOMOS datasets that will be used for our comparison. In Sect. 2, we will describe the main differences between MIPAS full- and reduced-resolution operation modes, with details about the instrument configuration and the measurement scenario adopted in the two cases. In Sect. 3, we will resume the key features of GOMOS ozone measurements, to be used as a benchmark for highlighting any change in MIPAS $\mathrm{O}_{3}$ products. A detailed description and justification of the strategy adopted for the continuity check of MIPAS $\mathrm{O}_{3}$ data quality is provided in Sect. 4. The results of the comparison will be discussed in Sect. 5. In
Sect. 6, we will present our conclusions about the quality of MIPAS ozone profiles retrieved from the reduced-spectralresolution measurements.

\section{MIPAS ozone measurements}

The MIPAS (Michelson Interferometer for Passive Atmospheric Sounding) instrument (Fischer et al. (2000), Fischer et al. (2007) and http://envisat.esa.int/dataproducts/mipas) is a Fourier transform infrared spectrometer operating onboard the ENVISAT satellite launched by ESA on 1 March 2002. MIPAS measures from space the limb thermal emission of the atmosphere in the middle infrared (from 685 to $2410 \mathrm{~cm}^{-1}$ ), a region containing a large fraction of the black body emission of the atmosphere as well as features due to the ro-vibrational spectra of most atmospheric constituents. The measured signal is integrated over the Instantaneous Field Of View (IFOV) of the instrument, equal to $3 \times 30 \mathrm{~km}^{2}$ (vertical height times across-track width, at $10 \mathrm{~km}$ tangent altitude). From July 2002 to March 2004 the instrument acquired nearly continuous limb scanning measurements with an interferometer Maximum Path Difference (MPD) equal to $20 \mathrm{~cm}$, corresponding to a spectral resolution of $0.025 \mathrm{~cm}^{-1}$. A spectrum was acquired in $4.5 \mathrm{~s}$ and a limb sequence in the nominal observation mode was composed of 17 spectra that looked at different tangent altitudes from 6 to $68 \mathrm{~km}$, with a step of $3 \mathrm{~km}$ in the troposphere and lower stratosphere and of up to $8 \mathrm{~km}$ in the high stratosphere. The time necessary to acquire a whole limb sequence was $76.5 \mathrm{~s}$. During each orbit, MIPAS performed 75 limb sequences plus measurements for instrument calibration. The ESA level 2 operational analysis of the MIPAS spectra determines, from level $1 \mathrm{~b}$ calibrated spectra, the pressure and temperature 


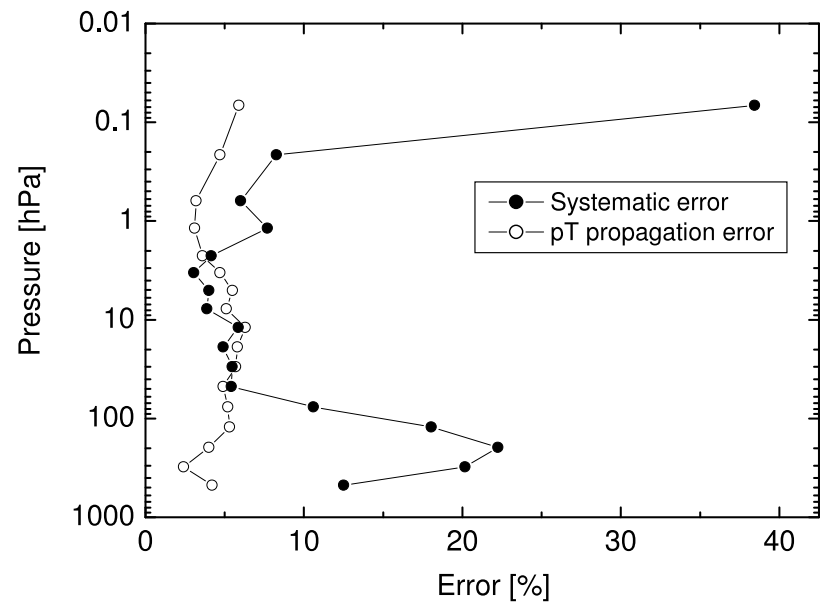

Fig. 1. Estimated systematic errors and errors propagated from the errors on pressure and temperature for the ozone profiles retrieved from full-spectral-resolution MIPAS measurements (in \%).

at tangent altitudes and the vertical profiles of six selected species (namely $\mathrm{O}_{3}, \mathrm{H}_{2} \mathrm{O}, \mathrm{CH}_{4}, \mathrm{HNO}_{3}, \mathrm{~N}_{2} \mathrm{O}$ and $\mathrm{NO}_{2}$ ) in the altitude range from 6 to $68 \mathrm{~km}$. The retrieval algorithm performs a Gauss-Newton non-linear least squares fit modified by the Levenberg-Marquardt method using a global fit strategy. The fit is performed on a selected set of spectral intervals (called "microwindows") that contain the maximum information on the species to be retrieved. A detailed description of the used algorithm can be found in the works of Ridolfi et al. (2000) and of Raspollini et al. (2006). Investigations on anomalies occurred in the interferometer slide speed showed a mechanical degradation of the instrument. In order to prevent the risk of a fatal blockage of the interferometer MIPAS was switched-off at the end of March 2004 and operations with a reduced MPD, equal to $8.2 \mathrm{~cm}$, and a reduced duty cycle (35\% "on" and 65\% "off") were resumed in January 2005. Subsequently, due to the reduction of the observed anomalies, the duty cycle has been increased stepwise to $80 \%$ "on" and $20 \%$ "off" and restored to $100 \%$ "on" since 1 December 2007. The interferograms acquired with reduced MPD are Fourier-transformed in spectra and re-sampled with a spectral resolution of $0.0625 \mathrm{~cm}^{-1}$, with a reduction of a factor 2.5 with respect to the original one. Because of the smaller value of the MPD also a reduction of the measurement time from $4.5 \mathrm{~s}$ to $2.1 \mathrm{~s}$ is obtained. This reduction in measurement time is exploited adopting an observation scenario with a finer vertical measurement grid and with more frequent limb sequences. Furthermore, for the new operation mode it was decided to adopt a floating altitude-sampling grid, in order to follow roughly the tropopause height along the orbit with the requirement to collect at least one spectrum per sequence within the troposphere, while avoiding too many cloud-affected spectra which give problems in the

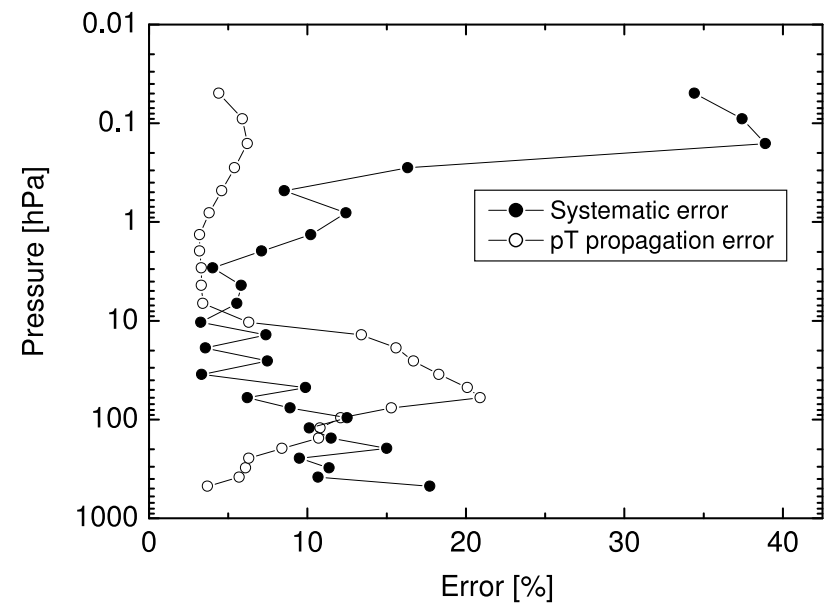

Fig. 2. Estimated systematic errors and errors propagated from the errors on pressure and temperature for the ozone profiles retrieved from reduced-spectral-resolution MIPAS measurements (in \%).

analysis. In the nominal observation mode adopted after January 2005, a MIPAS limb scan consists of 27 spectra that look at different tangent altitudes from 7 to $72 \mathrm{~km}$ with a step of $1.5 \mathrm{~km}$ in the troposphere and lower stratosphere and of up to $4.5 \mathrm{~km}$ in the high stratosphere. After January 2005 a significant fraction of MIPAS measurements was acquired in the special observation mode UTLS-1 (Upper Troposphere Lower Stratosphere-1), that was planned to study the upper troposphere and lower stratosphere region. The acquisition time of a limb sequence is $56.7 \mathrm{~s}$ and $39.9 \mathrm{~s}$ for the nominal and for the UTLS-1 mode respectively. In Table 1 the comparison between the nominal observation mode adopted before January 2005 and the nominal and UTLS-1 observation modes adopted after January 2005 is reported.

The MIPAS measurements acquired from July 2002 to March 2004 were analyzed in near real time and subsequently an off-line reprocessing of the data was performed. The off-line analysis used the same processor as the near real time analysis but different auxiliary data that allowed to obtain more accurate results at the expenses of an increased computing time. In this paper only the ozone data retrieved off-line with processor versions v4.61 and v4.62 will be used for the comparison. These data have been thoroughly validated by comparison with a large suite of correlative data from ground-based stations, aircraft and balloon-borne platforms, as well as concurrent satellite measurements and assimilated ozone fields. The results of this extensive validation effort are described in Cortesi et al. (2007) and demonstrate the high quality of MIPAS ozone profiles in the altitude range between 20 and $55 \mathrm{~km}$, with bias and precision within the current estimate of MIPAS systematic and random errors.

The MIPAS measurements acquired after January 2005 are characterized by a step of the vertical measurement 
grid that at low altitudes is smaller than the vertical IFOV, therefore contiguous limb scanning views are overlapping. This situation, combined with the choice of a retrieval grid that matches the measurement grid, determines an illconditioning of the inversion and the need for a regularization in order to avoid instabilities in the retrieved profiles. For this reason the MIPAS retrieval algorithm has been modified by introducing a Tikhonov regularization, whose strength is determined by means of the error consistence method (Ceccherini, 2005 and Ceccherini et al., 2007). Because of the finer measurement and retrieval grids and of the weakness of the adopted regularization, the ozone profiles retrieved from measurements acquired after January 2005 have an improved vertical resolution with respect to those retrieved from measurements acquired before January 2005 (Ceccherini et al., 2006). For the analysis of the MIPAS measurements acquired after January 2005 a new set of microwindows (optimized for the new measurement mode) for the ozone retrieval has been selected. In particular, a larger number of spectral points is considered (3035 for reduced-spectral-resolution measurements with respect to 2006 for full-spectral-resolution measurements), in order to compensate for the loss of information content caused by the reduced-spectral-resolution. The microwindows used for the retrieval of MIPAS full- and reduced-spectral-resolution measurements were provided by University of Oxford (Dudhia et al., 2002) and are reported in Tables 2 and 3 respectively. Only a sub-set of spectral points within these microwindows is used in the fitting procedure, for optimal exploitation of the information content of the spectra

The use of different microwindows for measurements acquired with full- and reduced-spectral-resolution determines different systematic errors and different errors propagated from the errors on pressure and temperature for the ozone profiles.

Figs. 1 and 2 show the estimated systematic errors and the errors propagated from the uncertainties on pressure and temperature for the ozone profiles retrieved from full- and reduced-spectral-resolution MIPAS measurements. We recall that in the case of MIPAS a sequential analysis of the individual target is made. Therefore, the results of pressure/temperature retrieval are used in the subsequent retrievals of the minor constituents and, accordingly, the propagation of the associated errors must be accounted for the error budget.

MIPAS reduced-spectral-resolution measurements acquired after January 2005 have not yet been processed with the ESA operational processor. However, a subset of the acquired measurements has been analyzed using the prototypes MIGSP 2.7 for level $1 \mathrm{~b}$ and ML2PP/5.0 for level 2 and distributed to the scientific community. Therefore, the ozone profiles retrieved from MIPAS measurements acquired during 140 ENVISAT orbits from January 2005 to May 2006 in either nominal (18 profiles) or UTLS-1 (68 profiles) modes are available and have been used for the comparisons re- ported in this paper. The same dataset has been used in other validation studies, e.g. for comparison with the ACE-FTS ozone measurements (Dupuy et al., 2008).

\section{GOMOS ozone measurements}

GOMOS (Global Ozone Monitoring by Occultation of Stars) is a stellar occultation instrument onboard the ENVISAT satellite (see Bertaux et al. (1991), Bertaux et al. (2000), Bertaux et al. (2004), Kyrölä et al. (2004), Kyrölä et al. (2006), and http://envisat.esa.int/dataproducts/gomos). The starting altitude is $130 \mathrm{~km}$ and the first few measurements are used to determine the star's undisturbed spectrum (the reference spectrum). The integration time is $0.5 \mathrm{~s}$, which gives the altitude sampling resolution $0.5-1.6 \mathrm{~km}$ depending on the altitude and the azimuth angle of the measurement. The GOMOS instrument has a large scanning mirror controlled by a star tracker. Light is forwarded through a slit to the two holographic gratings and to two fast photometers. During nighttime measurements the slit is not needed but during daytime measurements the slit restricts the intrusion of scattered solar light into the instrument. For daytime observations the scattered solar light increases the measurement noise in occultation retrievals (Verronen et al., 2007).

The spectrally resolved light is recorded by CCD (Charge Coupled Device) detectors. The spectral ranges are 250 $690 \mathrm{~nm}, 750-776 \mathrm{~nm}$, and $916-956 \mathrm{~nm}$, which enable retrieval of vertical profiles of $\mathrm{O}_{3}, \mathrm{NO}_{2}, \mathrm{NO}_{3}, \mathrm{H}_{2} \mathrm{O}, \mathrm{O}_{2}$, neutral density, and aerosols. The two photometers work at blue and red wavelengths at a frequency of $1 \mathrm{kHz}$. Photometer data are used to make the scintillation correction for the spectrometer data. From the photometer data it is also possible to retrieve high resolution (resolution of $200 \mathrm{~m}$ ) temperature profiles in the range of $15-40 \mathrm{~km}$ using the spatial separation of rays by chromatic refraction.

The geolocation of each GOMOS measurement is determined starting from the satellite location and from the known direction to the star, and performing the ray tracing calculation through the neutral atmosphere given by the ECMWF (European Centre for Medium-range Weather Forecasts) and MSISE-90 (Mass Spectrometer Incoherent Scattering). The upper limit of the ECMWF data in the current product is $1 \mathrm{hPa}$ (about $45 \mathrm{~km}$ ). The MSISE-90 is joined to ECMWF data in such a way that a hydrostatic equilibrium is preserved.

In GOMOS level 1 the basic calibration corrections are performed. The most important is the dark current removal that is made using the dark current measurements at every orbit. In GOMOS level 2 processing the transmission spectra are corrected first for the refractive attenuation caused by refraction and modulations by scintillations. The fast photometer data are used in the scintillation correction. The correction does not remove the scintillation modulation completely, but the ozone retrieval is only weakly sensitive to modulations by scintillations. 
Table 2. Microwindows used for the retrieval of MIPAS full-spectral-resolution measurements. For each microwindow the altitude range where it is used is reported, along with the corresponding approximate pressure values.

\begin{tabular}{llll}
\hline Microwindows label & $\begin{array}{l}\text { Spectral range } \\
{\left[\mathrm{cm}^{-1}\right]}\end{array}$ & $\begin{array}{l}\text { Altitude range } \\
{[\mathrm{km}]}\end{array}$ & $\begin{array}{l}\text { Pressure Range } \\
{[\mathrm{hPa}]}\end{array}$ \\
\hline O3_-_021 & $763.3750-766.3750$ & $6.0-68.0$ & $4.7310^{2}-6.7210^{-2}$ \\
O3_-013 & $1039.3750-1040.3250$ & $52.0-68.0$ & $6.2410^{-1}-6.7210^{-2}$ \\
O3_-_001 & $1122.8000-1125.8000$ & $6.0-68.0$ & $4.7310^{2}-6.7210^{-2}$ \\
\hline
\end{tabular}

Table 3. Microwindows used for the retrieval of MIPAS reduced-spectral-resolution measurements. For each microwindow the altitude range where it is used is reported, along with the corresponding approximate pressure values.

\begin{tabular}{llll}
\hline Microwindows label & $\begin{array}{l}\text { Spectral range } \\
{\left[\mathrm{cm}^{-1}\right]}\end{array}$ & $\begin{array}{l}\text { Altitude range } \\
{[\mathrm{km}]}\end{array}$ & $\begin{array}{l}\text { Pressure Range } \\
{[\mathrm{hPa}]}\end{array}$ \\
\hline O3__-334 & $729.2500-732.2500$ & $15.0-46.0$ & $1.2210^{2}-1.3410^{0}$ \\
O3_-_335 & $756.6250-759.6250$ & $7.5-37.0$ & $3.8410^{2}-4.3910^{0}$ \\
O3_-332 & $1033.1875-1036.1875$ & $31.0-70.0$ & $1.0310^{1}-4.9710^{-2}$ \\
O3_-_333 & $1117.0000-1120.0000$ & $6.0-46.0$ & $4.7310^{2}-1.3410^{0}$ \\
O3_-331 & $1123.5625-1126.5625$ & $7.5-70.0$ & $3.8410^{2}-4.9710^{-2}$ \\
\hline
\end{tabular}

In the spectral inversion, the model transmission function is fitted to the refraction-corrected transmissions simultaneously at all wavelengths by a non-linear LevenbergMarquardt method (Kyrölä et al., 1993, Sihvola, 1994). This absolute cross-section method had to be modified after it was realized that so-called isotropic scintillations modify transmissions in such a way that the scintillation correction method is not able to eliminate them. Therefore $\mathrm{NO}_{2}$ and $\mathrm{NO}_{3}$ retrieval is now based on sub-iteration using differential cross-sections (Hauchecorne et al., 2005). The vertical inversion is performed using the onion-peeling method. A smoothness constraint is applied to the inversion using the target resolution Tikhonov method (Sofieva et al., 2004). For ozone the target vertical resolution is $2 \mathrm{~km}$ below $30 \mathrm{~km}$, increases linearly to $3 \mathrm{~km}$ at $40 \mathrm{~km}$, and remains the same above that. An iteration loop over spectral and vertical inversion is performed in order to take into account the temperature dependence of the cross-sections.

The random error estimation is based on the propagation of all level $1 \mathrm{~b}$ errors, largest contributors of which are dark current and photon noise, through the spectral and vertical inversions. An additional error source in level 2 is the step where intensity fluctuations from scintillations are removed using photometer data. This additional error is estimated from large numbers of equatorial measurements with varying azimuth angle. The underlying assumption is that the ozone distribution around the equator is relatively constant and the variability of ozone profiles comes from the scintillations. The degree of scintillation error depends on the azimuth angle. The additional scintillation error seems to be overestimated in the GOMOS product used in this work (level 2 version 5.00), see Sofieva et al. (2007). The validity regions of retrieved constituents vary, depending on the type of the occulted star and on the state of the atmosphere. The valid altitude range of ozone retrievals is generally $15-$ $100 \mathrm{~km}$ with the exception of weak and cool stars that provide valid profiles only up to $45 \mathrm{~km}$.

The GOMOS data validation activity has been carried out since the summer of 2002. The comprehensive validation of ozone against ground-based and balloon-borne instruments has been presented in Meijer et al. (2004). The results show that in dark limb the GOMOS data agree very well with the correlative data: between 14 and $64 \mathrm{~km}$ altitude their differences show only a small (2.5-7.5\%) insignificant negative bias with a standard deviation of $11-16 \%(19-63 \mathrm{~km})$. This conclusion was demonstrated to be independent of the star temperature and magnitude and the latitudinal region of the GOMOS observation, with the exception of a slightly larger bias in the polar regions at altitudes between 35 and $45 \mathrm{~km}$.

In May-June 2003 GOMOS suffered a temporary electronic malfunction of the mirror steering mechanism. By using the redundancy in GOMOS electronics measurements were able to continue in July 2003 without loss of performance. A similar but more serious problem was encountered in January 2005. After a tedious testing phase measurements were resumed in the end of August 2005 but with a restricted pointing range (Barbieri et al., 2006). The number of available targets per orbit decreased to $65 \%$ of the original number. Because of the pointing range restriction the selection of stars has changed considerably in any latitudinal belt. For 


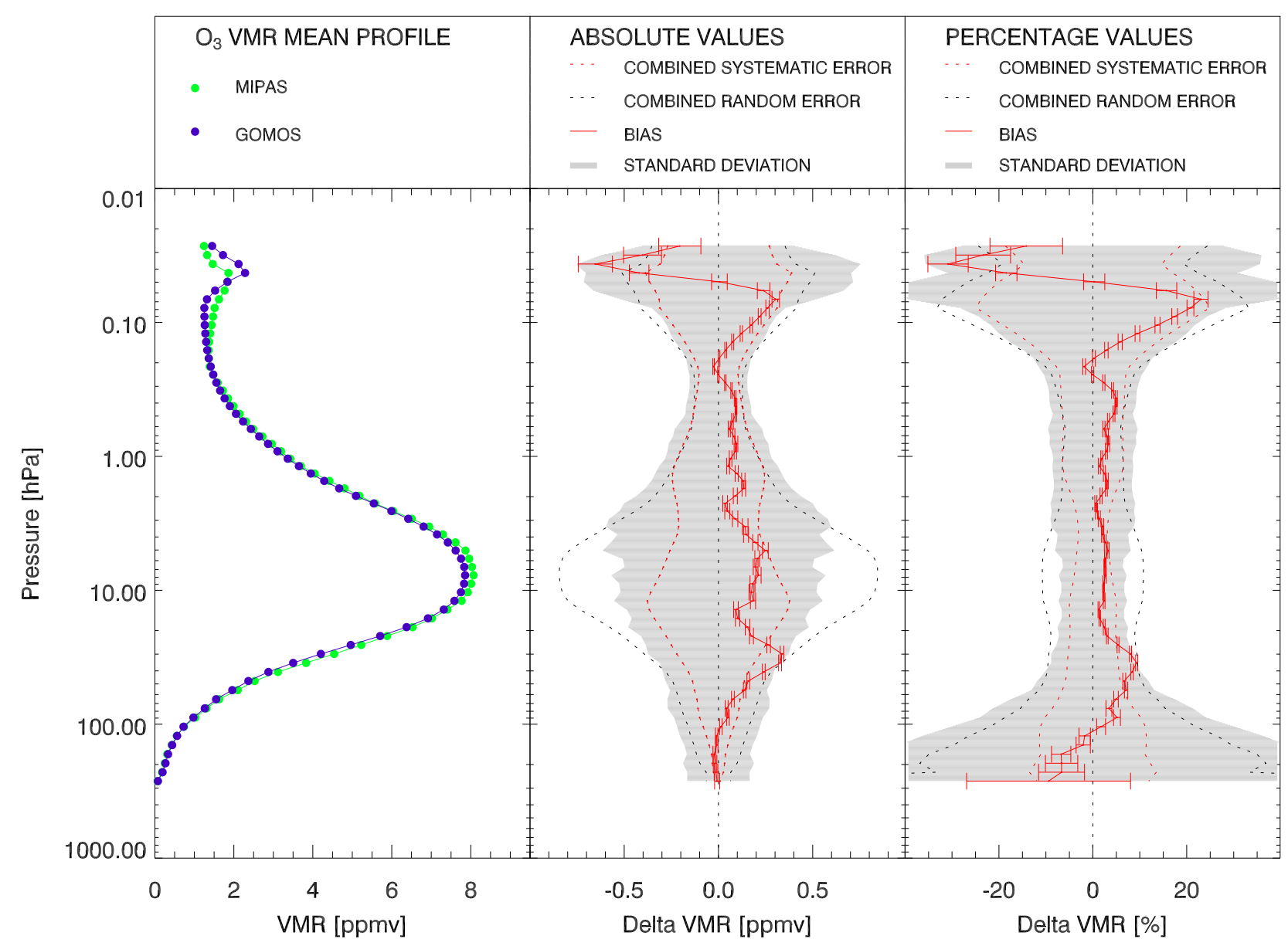

Fig. 3. Results of the comparison for the period of MIPAS full-spectral-resolution measurements (2003-2004). The left panel shows the MIPAS and GOMOS ozone VMR mean profiles. $\mathrm{O}_{3}$ VMR differences between MIPAS and GOMOS and associated uncertainties are plotted in the middle panel (absolute values in ppmv) and in the right panel (relative values as a percentage of GOMOS $\mathrm{O}_{3} \mathrm{VMR}_{\mathrm{N}}$ mean profile). In each plot we display the bias (red solid line, with error bars representing the SEM values), the random (black dashed line) and systematic (red dashed line) errors of the bias and its standard deviation (shaded area).

example, the brightest star Sirius is no more used by GOMOS in the equatorial region.

The noise of the GOMOS CCDs has increased steadily since launch. This has led to increased measurement errors but the overall bias has not increased. However, there seems to be a slight decrease in the upper limits of the validity regions of weak, cool stars. The increased random noise is reflected in the estimated GOMOS errors.

In the current comparison, we have used night-time data exclusively. This selection was made by requiring the solar zenith angle of the measurement tangent point to be $110 \mathrm{de}-$ grees or larger. To assure the reliability of the ozone data in the full altitude range, we selected target stars according to the recommendation of Kyrölä et al. (2006). The stellar magnitude was required to be $7000 \mathrm{~K}$ or larger, and the stellar visual magnitude was required to be 1.9 or smaller.

\section{Validation strategy}

The strategy adopted for the validation of ozone vertical profiles retrieved from MIPAS reduced-spectral-resolution measurements was based on the comparison of MIPAS full- and reduced-resolution level 2 products against coincident ozone data from GOMOS. This approach relied on the fact that:

(a) GOMOS data quality stayed reasonably stable, without suffering any major discontinuity in the period 20032006;

(b) MIPAS ozone operational products (v4.61 and v4.62), for the period July 2002-March 2004, have already been validated, as already mentioned in the previous sections (see, for instance, Sect. 2).

As a consequence, we can check the impact of the implemented changes in MIPAS measurement mode on the quality 


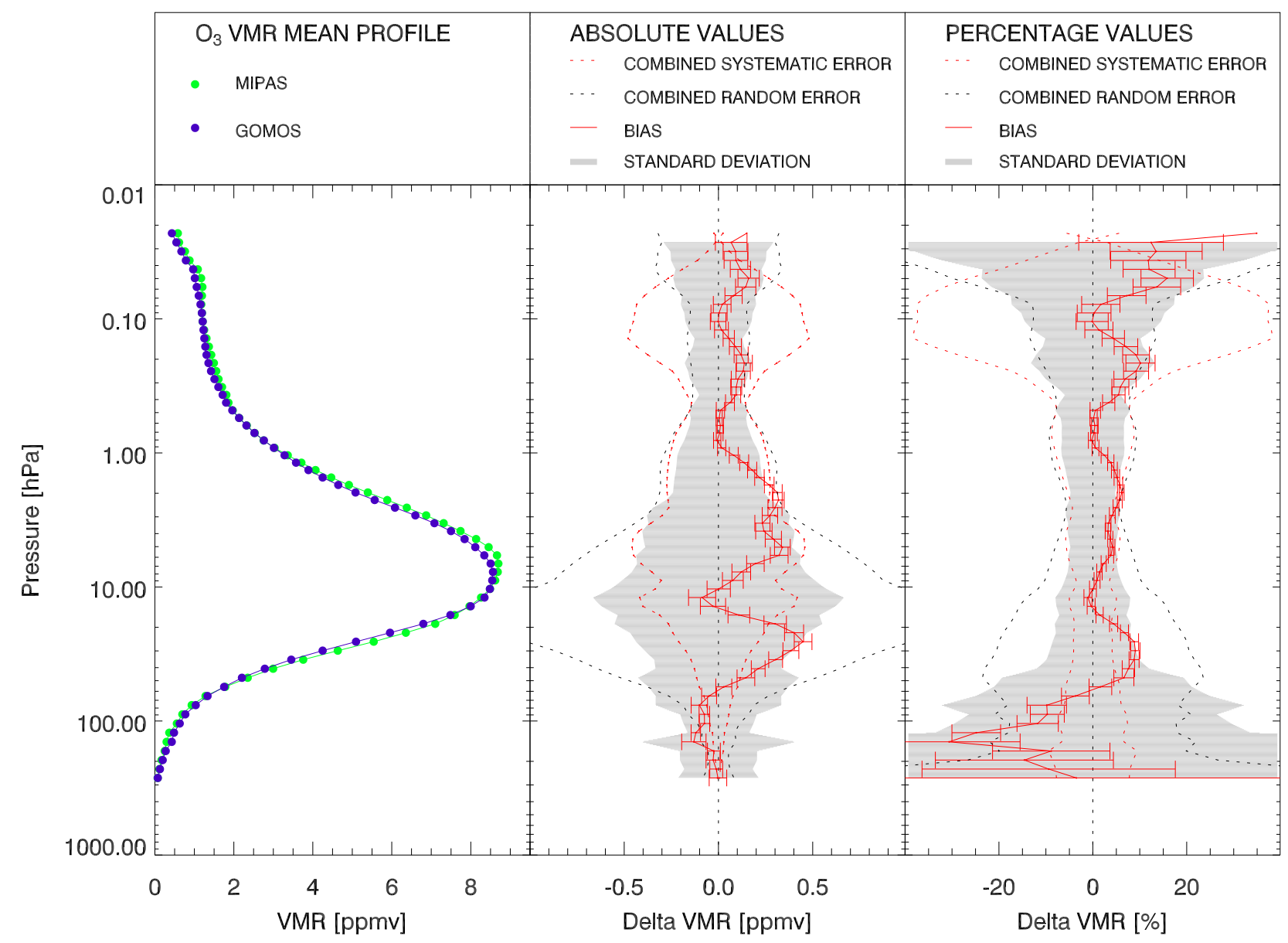

Fig. 4. Results of the comparison for the period of MIPAS reduced-spectral-resolution measurements (2005-2006). The format of the plots is the same as in Fig. 3.

of level 2 geophysical products, by comparing coincident MIPAS and GOMOS ozone profiles acquired in 2003-2004 and in 2005-2006. Any discrepancy between the outcomes of the comparison of the two datasets can be attributed to alterations in MIPAS data quality after the gap in instrument operations occurred between March 2004 and January 2005.

We required that coincident pairs of GOMOS and MIPAS ozone profiles satisfy the following spatial and temporal matching criteria:

- the spatial separation between coincident profiles should not exceed 3 degrees in latitude and 6 degrees in longitude;

- the time delay between coincident profiles should not be larger than 3 hours.

We also verified that the comparison pairs selected on the basis of the above mentioned criteria did not include profiles acquired by MIPAS and GOMOS on opposite sides of the polar vortex boundary. It was not necessary, therefore, to apply additional matching criteria for filtering coincident profiles acquired in regions of strong horizontal gradients. A subset of MIPAS ozone profiles (and coincident GOMOS data) was chosen from the operational products available for the full-resolution mission (see Sect. 5 for more details), whilst the entire ensemble of MIPAS ozone data provided by ESA for validation purposes was considered for the reducedresolution measurements.

The comparison was based on the calculation of both absolute and relative differences between vertical profiles of ozone VMR retrieved from coincident measurements of MIPAS and GOMOS. $\mathrm{O}_{3}$ VMR differences, computed from individual comparison pairs, were used to evaluate the bias:

$b_{j}=\frac{1}{N_{j}} \sum_{i=1}^{N_{j}}\left[x_{i j}^{\mathrm{MIPAS}}-x_{i j}^{\mathrm{GOMOS}}\right]$

where $b_{j}$ and $N_{j}$ are the bias and the number of comparison pairs for the $j^{\text {th }}$ pressure level of the common vertical grid used for interpolating MIPAS and GOMOS profiles (see 


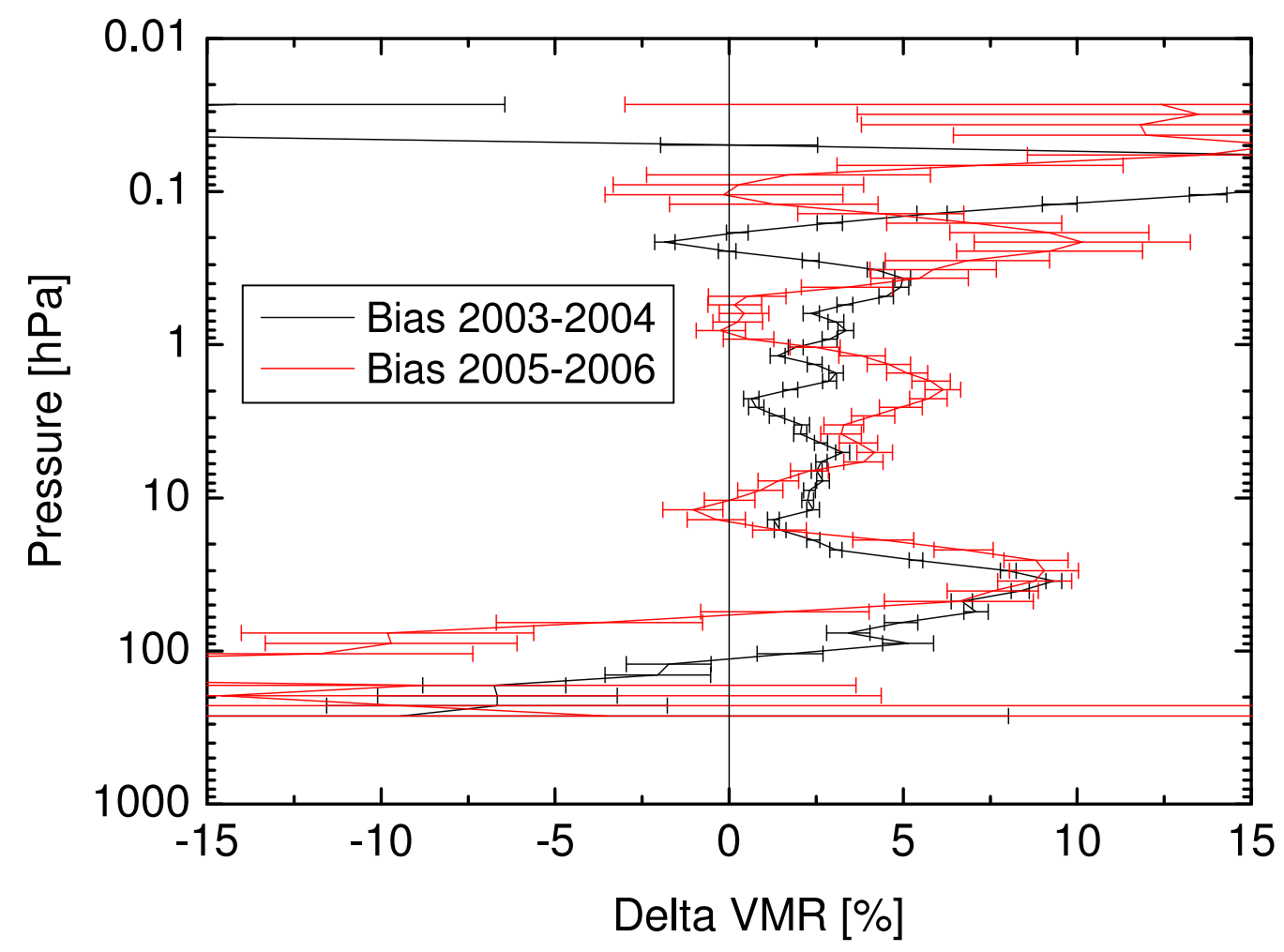

Fig. 5. Mean percentage difference between GOMOS and MIPAS ozone data (relative to the GOMOS mean profile) calculated for MIPAS full-resolution (2003-2004, in black) and reduced-resolution (2005-2006, in red) datasets.

Sect. 5 for details) and $x_{i j}^{\text {MIPAS }}$ and $x_{i j}^{\text {GOMOS }}$ are the ozone VMR values interpolated on the same level for the $i$ th pair of MIPAS and GOMOS profiles.

The uncertainty on the bias can be estimated from the Standard Error on the Mean (SEM):

$\mathrm{SEM}_{j}=\frac{\sigma_{j}}{\sqrt{N_{j}}}$

where $\sigma_{j}$ is the standard deviation of the bias $b_{j}$ :

$\sigma_{j}=\sqrt{\frac{\sum_{i=1}^{N_{j}}\left[x_{i j}^{\mathrm{MIPAS}}-x_{i j}^{\mathrm{GOMOS}}-b_{j}\right]^{2}}{\left(N_{j}-1\right)}}$

with associated uncertainty $\Delta \sigma_{j}$ (see, for instance, Sivia, 1996):

$\Delta \sigma_{j}=\frac{\sigma_{j}}{\sqrt{2\left(N_{j}-1\right)}}$.

The relative values for the above quantitities have been calculated as a percentage of the GOMOS $\mathrm{O}_{3}$ mean profile.

\section{Results and discussion}

In this section we will describe the results of the comparisons between GOMOS and MIPAS ozone profiles and we will try to highlight potential differences in the quality of MIPAS products retrieved from measurements at full- and at reduced-spectral-resolution. In Fig. 3 we show the overall result of the comparison for the period of MIPAS full-spectralresolution measurements. In this case, we compared 1633 coincident pairs of MIPAS and GOMOS $\mathrm{O}_{3}$ profiles acquired during 2003-2004: one month of data was selected for each season - i.e. April 2003 (63 pairs), July 2003 (125 pairs), October 2003 (541 pairs) and January 2004 (904 pairs) - and average values were calculated on the resulting dataset. $\mathrm{O}_{3}$ VMR differences averaged over the individual months (not shown here) provided similar results with no evidence of seasonal effects. In the left panel of Fig. 3, mean vertical profiles of ozone VMR obtained by MIPAS and by GOMOS are plotted. Mean values are calculated by averaging individual profiles interpolated on a common pressure grid (built from climatological values for mid-latitude/Spring conditions, with pressure levels corresponding to the range from 5 to $75 \mathrm{~km}$ in steps of $1 \mathrm{~km}$ ). In the middle panel, we report the mean absolute difference (in ppmv) between MIPAS and GOMOS ozone VMR as a function of pressure (red solid line), with error bars representing the SEM values. The combined systematic (red dashed line) and random (black dashed line) errors of the $\mathrm{O}_{3}$ VMR differences, as estimated from the corresponding components of MIPAS and GOMOS uncertainties, 


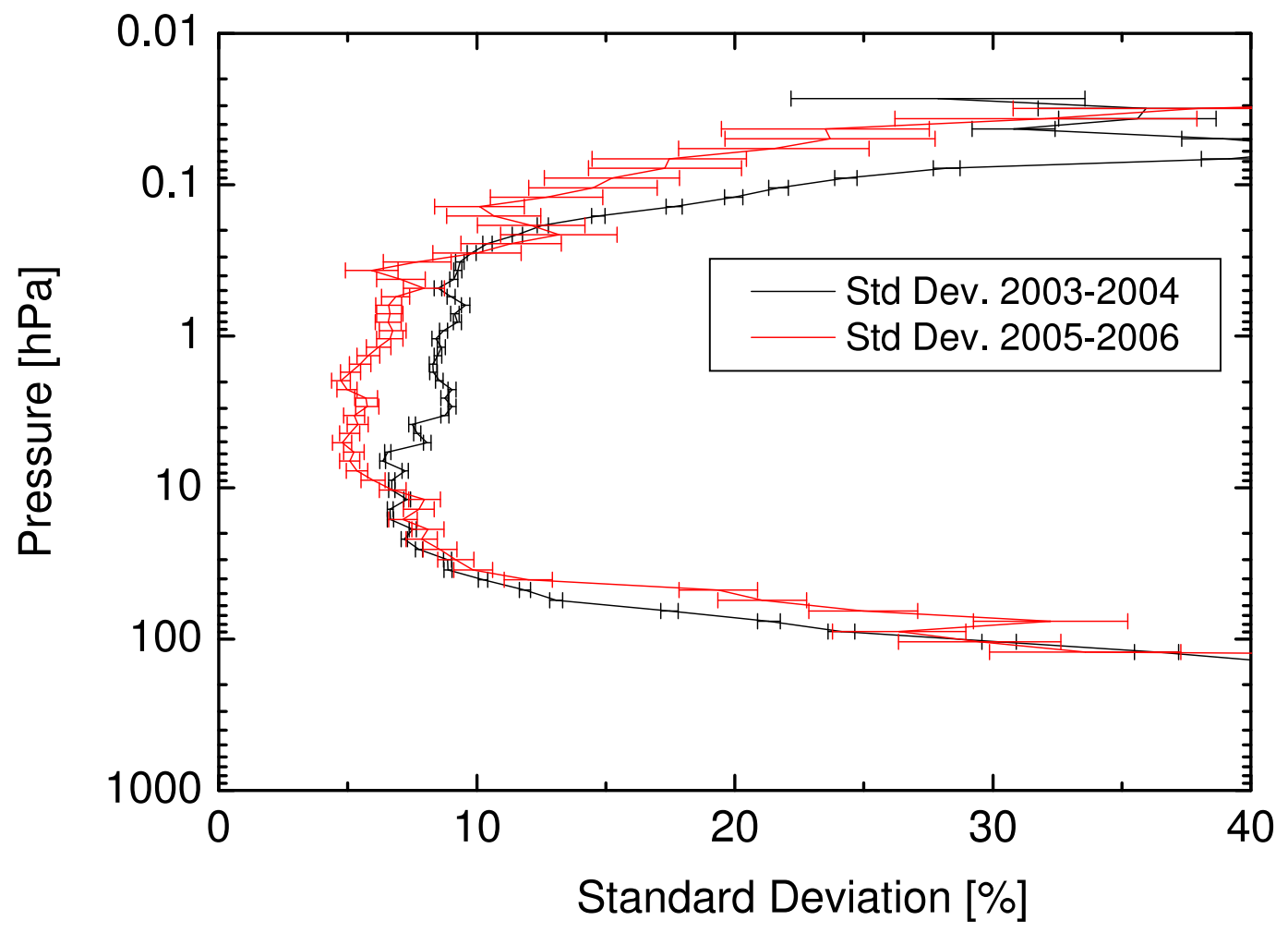

Fig. 6. Standard deviation of the differences between GOMOS and MIPAS ozone profiles as a percentage of the GOMOS mean profile, calculated for MIPAS full-resolution (2003-2004, in black) and reduced-resolution (2005-2006, in red) datasets.

are overplotted and can be compared with the mean profile of the $\mathrm{O}_{3}$ VMR difference and with its standard deviation (shaded area) respectively for bias and precision validation purposes. It is important to notice that the combined systematic error only includes the estimate of systematic effects on MIPAS ozone retrieval, as a detailed evaluation of systematic uncertainties on GOMOS ozone profiles are not available at the time of our analysis. In the right panel, a similar plot is presented, displaying the same quantities (VMR differences and errors) of the middle panel expressed as percentage of the GOMOS mean profile. The mean profile of the difference between MIPAS and GOMOS $\mathrm{O}_{3}$ VMR appears to be within the combined systematic errors of the comparison from the upper troposphere up to the lower mesosphere, with the only significant exception of the pressure layer around $40 \mathrm{hPa}$, where a positive bias of $\sim 10 \%$ is found. This bias can be, however, partly explained by considering that the contribution of GOMOS error budget is currently not included in the estimate of the systematic errors reported in Fig. 3 and that a rough estimate of this component (a few percent) can account for the exceedingly large values of the mean difference at $40 \mathrm{hPa}$. The current estimate of the combined random errors, on the other hand, is fully consistent with the precision of the comparison in the pressure range $3-40 \mathrm{hPa}$. Minor discrepancies (with the standard deviation of the bias larger than the random error by up to a factor of 2.5) are observed outside this range, especially at lower altitudes.

The overall outcome of the comparison confirms the good quality of ozone products from MIPAS full-spectralresolution mission. In particular:

(a) the estimate for the bias is less than $5 \%$ from $25 \mathrm{hPa}$ to $0.2 \mathrm{hPa}$ and between $5 \%$ and $10 \%$ for pressure values larger than $25 \mathrm{hPa}$ and less than $0.1 \mathrm{hPa}$. This result is in agreement with the outcomes of MIPAS ozone validation activity (Cortesi et al., 2007), as well as with an independent assessment of MIPAS ozone data quality performed in the frame of the ASSET (ASSimilation of Envisat daTa) project, as described by Lahoz et al. (2007);

(b) the precision of the comparison is between $6 \%$ and $10 \%$ in the range from $40 \mathrm{hPa}$ to $0.25 \mathrm{hPa}$.

The same comparison was performed on the set of ozone profiles available for the period of MIPAS reduced-resolution mission. In this case, a total number of 86 coincident pairs was considered, as already described in details in Sect. 2. The results of the comparison are displayed in Fig. 4.

As evident from the plots of the mean absolute and percentage differences between MIPAS and GOMOS $\mathrm{O}_{3}$ VMR 
values reported in the middle and in the right panel respectively, the bias is always within the current estimate of MIPAS systematic error, if we exclude the pressure levels between $20 \mathrm{hPa}$ and $50 \mathrm{hPa}$. The larger values of the bias observed in this layer could still be within the combined systematic error of the comparison, when including the missing contribution from GOMOS, consistently with what we have previously observed for MIPAS full-resolution mission. Also in this case, the precision of the comparison is less than the combined random error for pressure values less than $65 \mathrm{hPa}$. The standard deviation of the mean difference increases at lower altitudes up to a factor 3 of the random error. It is worth noticing that the estimated random error is much larger than the observed precision around $20 \mathrm{hPa}$; this feature can be explained, taking into account that the component of MIPAS error budget due to $\mathrm{pT}$ propagation error shows a peak approximately at the same level (see Fig. 2) and has been considered, in our calculation, as a purely random error. If this is not the case and if the pressure/temperature propagation error, for the selected dataset, is contributing to the bias and shall be considered as part of the systematic error of the comparison, we will tend to overestimate the random uncertainties as observed in Fig. 4.

In general, the overall result of the comparison for the dataset of MIPAS reduced-resolution measurements can be summarized by estimating a bias less than $5 \%$ in the pressure range from $0.4 \mathrm{hPa}$ to $20 \mathrm{hPa}$, excluding the layer around $\sim 2 \mathrm{hPa}$, where a larger bias $(\sim 6 \%)$ is observed, and within $10 \%$ in the stratosphere for pressure values smaller than $100 \mathrm{hPa}$. The precision error, on the other hand, appears to be between $5 \%$ and $10 \%$ in the range $0.28 \mathrm{hPa}$ to $40 \mathrm{hPa}$.

To better visualize the results of the comparison between MIPAS ozone data quality at full- and reduced-spectralresolution, we report the vertical profiles of the bias and of the precision error for the two datasets in Fig. 5 and in Fig. 6 respectively. The error bars represent the uncertainties on the bias and on the precision estimated as described in Sect. 4.

A similar behaviour is observed in the results of the comparison for 2003-2004 and for 2005-2006 in the lower stratosphere, with relatively high values of the bias up to $\sim 10 \%$ around $40 \mathrm{hPa}$.

A peak of the bias is also observed between 1 and $2 \mathrm{hPa}$, both in the 2003-2004 (3\%) and in the 2005-2006 (6\%) datasets, whilst the results of MIPAS reduced-resolution measurements provide a better agreement with GOMOS around $12 \mathrm{hPa}$ and $0.7 \mathrm{hPa}$ (mean difference consistent with zero for 2005-2006 and about 3\% for 2003-2004). In the range from $10 \mathrm{hPa}$ to $0.3 \mathrm{hPa}$, the precision error is approximately constant for both the full-resolution and the reducedresolution datasets, with the latter providing slightly better performances (i.e. average precision value being $\sim 6 \%$ for 2005-2006 and $\sim 8 \%$ for 2003-2004). At pressure below $10 \mathrm{hPa}$ the reduced-resolution measurements show a precision error larger than, or equal to, that of the full-resolution measurements.

\section{Conclusions}

In this paper, we have compared ozone vertical profiles retrieved from GOMOS measurements with coincident data obtained by MIPAS during its full- and reduced-resolution mission, with the aim of verifying the continuity of MIPAS $\mathrm{O}_{3}$ data quality after instrument operations were stopped in March 2004 and subsequently resumed in January 2005. The results of the comparison for the period of MIPAS fullresolution measurements are fully consistent with the outcome of previous validation experiments: the bias is within the systematic error of the comparison throughout the whole profile from the lowest levels up to $0.05 \mathrm{hPa}$, except for a single layer around $40 \mathrm{hPa}$. The observed precision is explained by the a priori estimate for the random error of the comparison in the range from $3 \mathrm{hPa}$ to $40 \mathrm{hPa}$. We demonstrated that similar conclusions apply to the dataset of MIPAS reducedresolution measurements. In this case, we found that the bias is constantly less than $10 \%$ for the whole pressure range from $100 \mathrm{hPa}$ up to $0.05 \mathrm{hPa}$. In this range the bias is also consistent with the combined systematic error of the comparison, with the only exception of the layer around $40 \mathrm{hPa}$, as for the 2003-2004 measurements. The precision error is fully justified by the estimate of the combined random error for all levels with pressure values smaller than $65 \mathrm{hPa}$.

In general, the quality of the ozone profile retrieved from reduced-resolution measurements is comparable or better than that obtained from the full-resolution dataset. The only significant change in MIPAS performances is observed at pressure around $2 \mathrm{hPa}$, where the bias increases by a factor 2 from the 2003-2004 to 2005-2006 measurements. This effect can be attributed to different systematic errors affecting both the pressure-temperature and ozone retrievals because of the different spectral intervals selected for fulland reduced-resolution-mission. Based on these results the choice of the microwindows for ozone retrieval from MIPAS reduced-resolution spectra is being reconsidered. Preliminary tests have shown that by replacing the microwindow O3__332 (see Table 3) with O3__343 (corresponding to the spectral interval $[1043.8750-1046.8750] \mathrm{cm}^{-1}$ and used in the altitude range [27.0-70.0] km) leads to a reduction of approximately $50 \%$ of the bias between full- and reducedresolution ozone profiles at pressure around $2 \mathrm{hPa}$. Therefore, next re-processing of MIPAS reduced-resolution-data will be performed using microwindow O3__343 instead of O3_332. The key indication emerging as a result of the analysis conducted in this work is that the systematic errors of the ozone profiles retrieved from full-resolution measurements are different from those associated to the ozone profiles of the reduced resolution dataset. This information represents an important warning when a consistency between the two datasets is required, as in the case of long-term investigations. 
Acknowledgements. This study was partially supported by the ESA contract 17580/03/I-OL. MIPAS data were provided by the European Space Agency. The authors gratefully acknowledge T. Fehr and B. Carli for their helpful comments and suggestions.

Edited by: U. Pöschl

\section{References}

Barbieri, A., Diekmann, F. J., Fraisse, R., Frerick, R., J., Canela, M., and Saavedra de Miguel, L.: GOMOS In-Orbit Operations and Failure Recoveries, SPACEOPS 2006, 19-23 June 2006, Rome, Italy.

Bertaux, J. L., Mégie, G., Widemann, T.,Chassefiere, E., Pellinen, R., Kyrölä, E., Korpela, S., and Simon, P.: Monitoring of ozone trend by stellar occultations, The GOMOS instrument, Adv. Space Res., 11(3), 237-242, 1991.

Bertaux, J. L., Kyrölä, E., and Wehr, T.: Stellar occultation technique for atmospheric ozone monitoring: GOMOS on Envisat, Earth Obs. Q., 67, 17-20, 2000.

Bertaux, J. L., Hauchecorne, A., Dalaudier F., et al.: First results on GOMOS/Envisat, Adv. Space Res., 33, 1029-1035, 2004.

Ceccherini, S.: Analytical determination of the regularization parameter in the retrieval of atmospheric vertical profiles, Optics Letters, 30, 2554-2556, 2005.

Ceccherini, S., Belotti, C., Carli, B., Raspollini, P., and Ridolfi, M.: MIPAS new measurement scenario: enhanced vertical resolution and regularization, ESA Publication SP-628, European Space Agency, 2006.

Ceccherini, S., Belotti, C., Carli, B., Raspollini, P., and Ridolfi, M.: Technical Note: Regularization performances with the error consistency method in the case of retrieved atmospheric profiles, Atmos. Chem. Phys., 7, 1435-1440, 2007,

http://www.atmos-chem-phys.net/7/1435/2007/.

Cortesi, U., Lambert, J. C., De Clercq, C., Bianchini, G., Blumenstock, T., Bracher, A., Castelli, E., Catoire, V., Chance, K. V., De Mazière, M., Demoulin, P., Godin-Beekmann, S., Jones, N., Jucks, K., Keim, C., Kerzenmacher, T., Kuellmann, H., Kuttippurath, J., Iarlori, M., Liu, G. Y., Liu, Y., McDermid, I. S., Meijer, Y. J., Mencaraglia, F., Mikuteit, S., Oelhaf, H., Piccolo, C., Pirre, M., Raspollini, P., Ravegnani, F., Reburn, W. J., Redaelli, G., Remedios, J. J., Sembhi, H., Smale, D., Steck, T., Taddei, A., Varotsos, C., Vigouroux, C., Waterfall, A., Wetzel, G., and Wood, S.: Geophysical validation of MIPAS-ENVISAT ozone data, Atmos. Chem. Phys., 7, 1-61, 2007,

http://www.atmos-chem-phys.net/7/1/2007/.

Dudhia, A., V.L.Jay, C.D. Rodgers, Microwindow selection for high-spectral-resolution sounders, Appl. Opt., 41, 3665-3673, 2002.

Dupuy, E., Walker, K. A., Kar, J., et al. Validation of ozone measurements from the Atmospheric Chemistry Experiment (ACE), Atmos. Chem. Phys. Discuss., 8, 2513-2656, 2008, http://www.atmos-chem-phys-discuss.net/8/2513/2008/.

Fischer, H., Blom, C., Oelhaf, H., Carli, B., Carlotti, M., Delbouille, L., Ehhalt, D., Flaud, J.-M., Isaksen, I., Lopez-Puertas, M., McElroy, C. T., and Zander, R.: Envisat-MIPAS - An instrument for atmospheric chemistry and climate research, edited by:
C. Readings and R.A. Harris, ESA Publication SP-1229, European Space Agency, 2000.

Fischer, H., Birk, M., Blom, C., Carli, B., Carlotti, M., von Clarmann, T., Delbouille, L., Dudhia, A., Ehhalt, D., Endemann, M., Flaud, J. M., Gessner, R., Kleinert, A., Koopmann, R., Langen, J., López-Puertas, M., Mosner, P., Nett, H., Oelhaf, H., Perron, G., Remedios, J., Ridolfi, M., Stiller, G., and Zander, R.: MIPAS: an instrument for atmospheric and climate research, Atmos. Chem. Phys. Discuss., 7, 8795-8893, 2007,

http://www.atmos-chem-phys-discuss.net/7/8795/2007/.

Frerick, J., Canela, M., Diekmann, F. J., Rosen, J., Barbieri, A., Mosner, P.: MIPAS In-Orbit Operations and Failure Recoveries, SPACEOPS 2006, 19-23 June 2006, Rome, Italy.

Hauchecorne, A., Bertaux, J.-L., Dalaudier, F., Cot, C., Lebrun, J.C., Bekki, Marchand, S., Kyrölä, M., Tamminen, E., Sofieva, J. V., Fussen, D., Vanhellemont, F., Fanton d'Andon, O., Barret, G., Mangin, A., Theodore, B., Guirlet, M., Snoeij, P., Koopman, R., Saavedra de Miguel, L., Fraisse, R., and Renard, J.B.: First simultaneous global measurements of nighttime stratospheric $\mathrm{NO}_{2}$ and $\mathrm{NO}_{3}$ observed by Global Ozone Monitoring by Occultation of Stars (GOMOS)/Envisat in 2003, J. Geophys. Res., 110, D18301, doi:10.1029/2004JD005711, 2005.

Kyrölä, E., Sihvola, E., Kotivuori, Y., Tikka, M., Tuomi, T., and Haario, H.: Inverse theory for occultation measurements: 1. Spectral inversion, J. Geophys. Res., 98, 7367-7381, 1993.

Kyrölä, E., Tamminen, J., Leppelmeier, G. W., et al.: GOMOS on Envisat: An overview, Adv. Space Res., 33, 1020-1028, 2004.

Kyrölä, E., Tamminen, J., Leppelmeier, G. W., et al., Nighttime ozone profiles in the stratosphere and mesosphere by the Global Ozone Monitoring by Occultation of Stars on Envisat, J. Geophys. Res., 111, D24306, doi:10.1029/2006JD007193, 2006.

Meijer, Y. J., Swart, D. P. J., Allaart, M., Andersen, S. B., Bodeker, G., Boyd, I., Braathen, G., Calisesi, Y., Claude, H., Dorokhov, V., von der Gathen, P., Gil, M., Godin-Beekmann, S., Goutail, F., Hansen, G., Karpetchko, A., Keckhut, P., Kelder, H. M., Koelemeijer, R., Kois, B., Koopman, R. M., Kopp, G., Lambert, J.C., Leblanc, T., McDermid, I. S., Pal, S., Schets, H., Stubi, R., Suortti, T., Visconti, G., and Yela, M.: Pole-to-pole validation of Envisat GOMOS ozone profiles using data from groundbased and balloon sonde measurements, J. Geophys. Res., 109, D23305, doi:10.1029/2004JD004834, 2004.

Nett, H., Frarick, J., Paulsen, T., and Levrini, G.: The atmospheric instruments and their applications: GOMOS, MIPAS and SCIAMACHY, ESA Bulletin (ISSN 0376-4265), 106, 77-87, 2001.

Raspollini, P., Belotti, C., Burgess, A., Carli, B., Carlotti, M., Ceccherini, S., Dinelli, B. M., Dudhia, A., Flaud, J.-M., Funke, B., Hoepfner, M., Lopez-Puertas, M., Payne, V., Piccolo, C., Remedios, J. J., Ridolfi, M., and Spang, R.: MIPAS level 2 operational analysis, Atmos. Chem. Phys., 6, 5605-5630, 2006,

http://www.atmos-chem-phys.net/6/5605/2006/.

Ridolfi, M., Carli, B., Carlotti, M., von Clarmann, T., Dinelli, B. M., Dudhia, A., Flaud, J.-M., Höpfner, M., Morris, P. E., Raspollini, P., Stiller, G., and Wells, R. J.: Optimized forward model and retrieval scheme for MIPAS near-real-time data processing, Appl. Opt., 39, 1323-1340, 2000.

Sihvola, E.: Coupling of spectral and vertical inversion in the analysis of stellar occultation data, Geophys. Publ., 38, Finn. Meteorol. Inst., Helsinki, 1994. 
Sivia, D. S.: Data Analysis, A Bayesian Tutorial, Clarendon Press - Oxford, 1996.

Sofieva, V. F., Kyrölä, E., Dalaudier, F., et al.: Influence of scintillation on quality of ozone monitoring by GOMOS, Proceedings of the Envisat Symposium, ESA SP-636, Montreux, Switzerland, 23-27 April, 2007.

Sofieva, V. F., Tamminen, J., Haario, H., Kyrölä, E., and Lehtinen, M.: A priori smoothness on ozone profile smoothness in the inversion from limb measurements, Ann. Geophys., 22(10), 3411-3420, 2004.
Verronen, P. T., Kyrölä, E., Tamminen, J., et al.: A comparison of daytime and night-time ozone profiles from GOMOS and MIPAS, Proceedings of the Envisat Symposium, Montreux, Switzerland, 23-27 April, 2007. 